\title{
Representationalism and the Intentionality of Moods
}

\author{
Anthony Hatzimoysis ${ }^{1}$
}

Received: 22 September 2016 / Revised: 1 February 2017 / Accepted: 22 February 2017

(C) Springer Science+Business Media Dordrecht 2017

\begin{abstract}
It seems hard to comprehend how, during mood experience, the 'inner' meets the 'outer'. The objective of this paper is to show that a currently popular attempt at providing a neat solution to that problem fails. The attempt comes under the heading of representationalism, according to which the phenomenal aspects of mood are exhausted by its representational content. I examine three accounts of intentionality developed within the representationalist camp, and I show that they incur phenomenological and metaphysical costs.
\end{abstract}

Keywords Mood Emotion · Intentionality $\cdot$ Representationalism $\cdot$ Intentionalism

\section{Introduction}

Human beings are naturally attracted to change. Moods, as enduring occurrences of feeling, appear resistant to change. They thus go against a basic tenet of emotive experience: its following closely upon-rising after, attending to, or subsiding withalterations in one's environment. ${ }^{1}$

The apparent stability of moods might not be confused for absence of psychological activity; in a depressive mood, there might be disquiet, in an elated mood, excitation. However, being in a mood is a phenomenon often taken to present a challenge to the understanding of affective states as attuned to what unfolds in the outside world.

The standard way of articulating that challenge is in terms of intentionality, conceived as directedness at, or reference to, some object. It has been claimed, for instance,

${ }^{1}$ Cf. Ben-Ze'ev (2000) on the significance of change for emotional life.

Anthony Hatzimoysis

hatzimoysis@yahoo.com

1 History and Philosophy of Science Department, National and Kapodistrian University of Athens, 15771 Athens, Greece 
that moods mark a separate domain of the mental, precisely due to their lack of intentional connection to the world. ${ }^{2}$ In response to that claim, it has been argued that the appearance of such a lack is based on an inadequate phenomenology, and that a closer look at the relevant psychological events will reveal the worldly involvement lying at the core of the affective experience. ${ }^{3}$

I am myself sympathetic to the latter approach. As I have argued though, several models of intentionality, despite their technical acumen, fall short of providing a phenomenologically sound account of what it is like to be in an affective state. ${ }^{4}$ The main problem with such models is that they fail to accommodate the fact that being affectively engaged with something is experienced as a unitary state directed at that thing.

In the case of moods, the problem of producing a unified account of affective intentionality is accentuated due to a tension between two seemingly innocuous facts. On the one hand, it is evident that the mood experienced by a subject is not unrelated to how the world appears to her. On the other hand, it is not obvious in what sense a mood might be taken to be of or about anything, or as directed at some object.

What seems hard to comprehend is how, during mood experience, the 'inner' meets the 'outer'. The objective of this paper is to show that a currently popular attempt at providing a neat solution to that problem fails. The attempt comes under the heading of representationalism, according to which the phenomenal aspects of mood are exhausted by its representational content.

Representationalism is a general thesis about the phenomenal character of conscious experience, be it perceptual or affective. All there is to the phenomenal experience of seeing blue -according to reprentationalists- is the visual representation of something as blue. Visual experience of colour does not involve any colour "feels"; the phenomenal character, the "what it's like" of the visual state, is exhausted by its representational nature. Similarly, for representationalism, all there is to the phenomenology of a mood state, the "what it's like" to be, for instance, in a state of anxiety, is the representation of the peril one encounters. A representationalist about moods may assert that, as in the case of the phenomenology of seeing blue there is nothing more to the experience than the representation of something as blue, so in the case of a depressive mood, there is nothing more to the phenomenology of the experience than the representation of one's environment as devoid of prospects or significance.

I shall examine three accounts of intentionality developed within the representationalist camp, and I shall show that they incur serious phenomenological and metaphysical costs.

As a way of entering those issues, let me first make some general remarks which, in my view, should inform our discussion of moods. Keeping in mind those remarks may facilitate the inquiry into the phenomena that representationalists purport to explain; it will also help the reader assess the plausibility of the premises which ground my own analysis.

\footnotetext{
${ }^{2}$ Searle $(1983,2)$, Dretske (1995, xv), Deonna and Teroni $(2012,4)$.

${ }^{3}$ De Sousa (1987), Goldie (2000), DeLancey (2006).

${ }^{4}$ Hatzimoysis (2003a)
} 


\section{Standpoint}

A theory of moods should respect their distinctiveness as a type of affective experience. As affective experiences, moods have a phenomenal aspect that is primarily open to the first-person standpoint. The agent's own access to her mood is, in that sense, privileged. ${ }^{5}$ However, that fact does not preclude the significance of third-personal research. On the contrary, some aspects of mood, including its cognitive outlook and behavioral manifestations, may be illuminatingly interpreted by attendant observers or engaged interlocutors. ${ }^{6}$ When it comes to one's knowledge of one's own affective experience, "privileged" does not mean "exclusive".

Correspondingly, it is worth stressing the significance of the standpoint from which the discourse on mood is articulated. An emotion typically directs an agent's attention to the world outside herself; consequently, the agent's narration of her emotional state can employ the subject/object dichotomies which pertain, for instance, to the description of perceptual experience. ${ }^{7}$ In its turn, that type of discourse facilitates a sense of distance from one's own emotional state, which may increase the reliability of the subject's own narration.

In the case of moods, the epistemic situation of the agent is quite different. Mood is experienced as apparently both all-encompassing and irrevocably intimate. As allencompassing, mood seems to leave nothing out of its purview, thus rendering difficult the process of telling what is, from what is not, directly relevant to the arising or maintenance of that state. As irrevocably intimate, mood requires special effort for detaching oneself from its grip; hence, from a first-person standpoint, an impartial description of mood's characteristics is often hard to achieve.

Nevertheless, the phenomenal aspect of mood experience, the way it feels to be depressed or in a state of euphoria, is primordially open to the subject whose experience it is. Accordingly, our approach should strike a balance between the phenomenological starkness of third-person observations, and the narrative partiality of first-person descriptions. As we shall see, representationalism purports to resolve this problem, by treating the phenomenal aspects of affectivity as dependent upon, or even exhausted by, the features of the world represented by the mood experience.

\section{Distinctiveness}

No less significant is to attend to the distinctive character of mood experience. The methodological problem here is twofold. One is to brush over any differences between moods and emotions, recasting the former as a sub-type of the latter; such an approach ends up treating emotion as the sole occupant of a homogenous affective landscape. ${ }^{8}$ The other is to conceive of moods as constitutionally different from emotions, located at a different region of the mental domain, and deprived of the characteristics which give emotional experience its meaningfulness. That approach leads to what I would call

\footnotetext{
${ }^{5}$ On the current debate over the nature and limits of privileged access see Hatzimoysis (2011) and Neta (2011).

${ }^{6}$ Rattcliffe (2010) includes a good survey of the relevant empirical and interpretative research.

${ }^{7}$ That is, also, one of the considerations that can be adduced in support of perceptual accounts of emotion; cf. Elgin (1996), Roberts (2003), Deonna (2006).

${ }^{8}$ Delancey (2006); cf. Solomon (1993, 71), Frijda (1994, 60), Prinz (2004, 182-188), Fish (2005).
} 
a 'hybrid theory' of affectivity, which reserves exclusively higher-level features for emotion (intelligence, conceptuality, rationality), and leaves more primitive characteristics for moods (as causally overdetermined, non-conceptual, reflex phenomena). ${ }^{9}$

A related point concerns the debate over the intentionality of moods. Granted that emotions are intentional states -as I believe they are- and on the assumption that affectivity is not some disjoint, irregular domain -as I think it is not- it is inferred that moods, as part of that domain, share with emotive states one of their essential characteristics, i.e., their intentionality. ${ }^{10}$ The inference might reasonable, but its ground is not stable. Ideally, we would want our theory of mood phenomena to arise out of an exploration of the phenomena themselves; instead, what we are offered is a claim driven by a wish for theoretical completeness. The desire to present a rounded approach to mental phenomena may come at the price of misrepresenting some phenomena which might not be easily amenable to that approach. As we shall see, some representationalists are vulnerable to that challenge, because in their urge to reduce the phenomenal to the intentional, they do not devote sufficient time in establishing what needs to be shown in the first place, namely that moods are indeed intentional. It might be best, therefore, to approach the issue of intentionality of moods, as a distinctive kind of mental phenomena, through a different route.

\section{Intelligibility}

During affective experience, even when everything appears meaningless, the affect itself is not a meaningless occurrence. Every mood, be it positive, negative, or neutral, appears to have some significance. I would suggest that the significance of mood is double-arrowed: a mood indicates something for the life of the person undergoing the experience, while it points at a value laden aspect of the surrounding world. That "pointing at" is a kind of intentionality; and its invocation has explanatory value, because it helps to render the whole experience intelligible.

Citing the general peril that a person encounters, helps us to make sense of his mood of anxiety; invoking the offensives of the world he inhabits, renders intelligible his irritable mood. By correlating the experience with salient aspects of a situation, the intentionality of moods appears to enable our understanding why the person is in the mood that he is.

However, if that is the main reason why the notion of intentionality plays an important role in a theory of moods, then certain desiderata arise about the type of intentionality under consideration. On the one hand, it should be a type of relation whose invocation explains by justifying: an appeal to the intentional correlation between a situation of general peril and a mood of anxiety offers a rationalizing explanation. On the other hand, the intentionality of moods should refer to items which are in principle able to affect the person who is in a mood. If we were to try to correlate

\footnotetext{
${ }^{9}$ For approaches that adopt some version of that taxonomy see Griffiths (1997), Lormand (1985), Sizer (2000), Nussbaum (2001), and Price (2006). In my view, that approach is problematic not because the affective landscape is homogeneous, but because it is a taxonomy that locates the differences at the wrong level - sometimes differences between emotions are more pronounced than the difference between an emotion and its consequent mood.

${ }^{10}$ Cf. Crane's subtle argumentation in (Crane 1998) and (Crane 2013).
} 
a mood with an item that is impossible, by its very constitution, to affect anyone or anything, then we would fail to provide an explanation; hence, the alleged intentional relation between the mood and that item, would not render the mood intelligible.

The above desiderata leave room for a variety of theories about the intentionality of moods ${ }^{11}$; yet, they are far from trivial, since they set limits on the kind of items that can be intentionally correlated to a mood. As I will presently argue, some forms of representationalism seem to trespass those limits, thus failing to provide an account of intentionality that would help us make sense of the relevant experiences.

\section{Representationalism}

One of the things we desire of our theory of moods is that it make good metaphysical sense. Assuming that our metaphysics is naturalistic, it would be good if we could locate moods in the natural order of things. Moods involve several characteristics, most prominent of which is their phenomenality, the way it feels to the subject of experience to be in a mood. Traditionally, the phenomenal aspects of affective experience were set aside as a peculiar residuum of functionalist analysis, or as an unwanted item to be explained away by eliminative materialism. However, recent developments in the theory of intentionality have opened a different route: intentionality is the mark of the mental; all mental states are directed at some object; the intentional object is represented in the content of the mental state; the phenomenal aspects of a mental state are either identical to, or dependent upon, parts of the representational content. Given that a naturalistic account of how objects get mentally represented is already here, or soon forthcoming, we have a way for accommodating, in principle, the phenomenal through the representational within a naturalistic ontology. Moods are states with phenomenal aspects; those aspects can be accommodated by reducing them to, or rendering them dependent upon, their representational content; hence a naturalistically account of moods is readily available.

That is in a nutshell the representationalist approach. ${ }^{12}$ I shall focus here only on those aspects of the approach that bear directly upon the issue of moods.

Notice that the starting point of the representationalist analysis is not some question that arises while exploring the relevant affective experiences, but the issue of applicability of a ready-made theory to the case of moods. Methodologically, that is cause for some concern; it is not uncommon, in treating a range of phenomena as a mere obstacle to the success of a pre-established theory, to end up revising the phenomena themselves so as to make them fit into the constraints of our preferred theory.

That methodological concern is exacerbated if we reflect on one of the major considerations that drive representationalism about the mental. It is a widely-accepted fact that an attempt to focus on the phenomenal qualities of certain experiences - on what it is like to see something as a white, rectangular, smooth surface- will eventually take you to attend to the properties of the page you are observing. The attempt to switch attention from external objects and properties perceived, to the visual experience you are having, is almost certainly doomed to frustration. Representationalists claim that the

\footnotetext{
$\overline{11}$ Kenny (1963), Tappolet (2000), Terroni (2007).

${ }^{12}$ For a balanced discussion of the representationalist movement see Siewert (1998), (Siewert 2012).
} 
best explanation of the fact that one's attention goes though the perceptual experience to items of the external world is that the phenomenal properties of the experience consist in its representational properties. Whatever phenomenal content a visual experience enjoys, it is reducible to (identical with, or strongly supervenient upon) its representational content. ${ }^{13}$

I do not wish to dispute that line of reasoning. What is often missed, though, is that representationalism about visual experience functions as the default option because it is rightly considered to be in tune with naïve realism about external objects and their properties. Representationalism about visual experience, in other words, is in tune with the folk psychology of ordinary experience. But that is hardly the case with moods. Folk psychology treats moods as a deeply personal affair, and common sense expects that in inquiring about one's moods, one turns one's mental eye inwards.

Accordingly, a critic of representationalism may argue that when someone tries to focus on his mood state, his attention doesn't go out to the world; on the contrary, if he tries to focus on the world, he often ends up focusing only on his own state of mind. ${ }^{14}$ The critic may also claim that in attending to my experience of some mood, I focus directly on what it feels like to be in that mood. ${ }^{15}$ She may go further, in maintaining that focusing inwards may suffice for a proper understanding of the mood experience. ${ }^{16}$

Although I share the critics' concerns, I would not subscribe to the last claim. As I argued earlier on, an affective experience is not easily detachable from the world within which a person undergoes that experience. Banning from view the salient features of his situation, might make a person's experience very hard to comprehend; it might render it unintelligible. Hence, our reservations about representationalism should not make us lose sight of the positive aspects of that doctrine, most notably its attempt to highlight the interrelation between a person and the world, by means of the notion of intentionality of affective experience. Let us look, then, at the models of intentionality upheld by representationalists.

\section{Intentionality and the World}

The standard way to present the intentionality of a mental state is by citing the object at which it is directed. The object involved might occasionally be hard to specify. We may wonder, for instance, whether the intentional object of one's vision is the book in front of him, or the desk top, with all its items, which forms the perceptual background out which the object stands. We may also question whether the intentional object, as perceived, is identical to, or even dependent upon, the physical object lying on the desk. And we might doubt whether a commitment to intentionality extends to states, such as visualizing or optical recalling, whose content represents objects which are not present. In the case of visual perception, we may debate about those -and many otherissues, without disputing the one-to-one correlation between a particular mental state

\footnotetext{
13 The argument from transparency can be found in Harman (1990), developed in Tye (2002), elaborated by Byrne (2001). For the varieties of ontological dependency involved in supervenient claims see Hatzimoysis (2003b).

${ }^{14}$ De Sousa (2004), Deonna and Teroni (2012), 68-69).

${ }^{15}$ Kind (2014), 130).

${ }^{16}$ Kind's line of argumentation at (2014, 130-131) appears to me to imply as much.
} 
and a particular object, whether that object is as small as the tip of my pen, or as large as the front of a skyscraper.

In the case of moods, such a correlation looks difficult to sustain. At a minimum, it requires some effort to articulate an account of intentional content that would do justice to moods as a distinctive kind of affective experience. I shall focus here on three scenarios encountered in the representationalist literature.

The first candidate for an intentional object that is attributed to moods is the whole world. ${ }^{17}$ That proposal appears to do justice to the overwhelming character of many moods, the fact that moods pervade our experience, that they suffuse all aspects of our encounter with reality. However, taken literary, the suggestion that the world is the intentional object of our moods is, in my view, problematic for three reasons.

First, the proposal employs a notion that is not easy to determine. It is not clear whether we are invited to think of the world as a maximally inclusive situation encompassing all others, or perhaps as an object which has in it everything (except for itself), or as the totality of phenomena linked by a complex network of references to each other. It can be retorted that the proposal requires nothing more than a loose understanding of the term, as employed in ordinary contexts. However, that retort does not really answer our query; it rather shows that the appeal of the proposal trades on the multiple ambiguity of the basic term it employs.

Secondly, the proposal makes excessive demands on the representational capacities of ordinary subjects. An affective state that is intentionally correlated to the whole world would entail an ability to form representations that move well beyond the perspectival, partial, and limited access to one's immediate environment.

Finally, even if we manage to short out the above issues, the suggestion that moods are intentionally directed at the world founders on the problem of distinguishability between kinds of affective states. To be outraged with the whole world is not a mood: it is an intense (in its phenomenal quality) and global (in its intentional content) emotion.

\section{Intentionality and the Plurality of Objects}

The second proposal treats the generality of the intentional object in a distributive manner. Instead of setting one object (the whole world) as the intentional correlate of mood, it takes as object the members of a disjunctively defined set composed of anything that comes our way ${ }^{18}$; for any object encountered, we have, during a mood experience, a corresponding intentional relation.

That proposal has the advantage of offering a way of distinguishing between emotions (which are directed at a single object, be it a particular thing, person, event, or situation), and moods (which take an indeterminate plurality of objects).

\footnotetext{
${ }^{17}$ For Solomon, moods "are about the whole of our world" (Solomon 1976, 173), while for Lyons moods are "aimed out at the world" (Lyons 1980, 104); cf. Annette Baier (1990, 14).

${ }^{18}$ For Solomon, moods are "indiscriminately about anything that comes our way, casting happy glows or somber shadows on every object and incident of our experience" (Solomon 1976, 173); Solomon's proposal is in tune with theories which highlight the puzzling fact that moods appear to be directed at both nothing and everything; cf. Goldie (2000, 18), De Sousa (2010), and Sizer (2000, 747) and for discussion Kind (2014), 120).
} 
However, the proposal appears to me to fail on the issue of intelligibility. As we noted earlier, a major task for an account of intentionality is to help us make sense of the character of the relevant experience. By correlating the experience with its intentional target, the account should contribute to our understanding why the person is in the mood that he is. However, treating every different object in one's environment as the intentional object of mood, may render inexplicable why one is in the particular mood that he is. Let me explicate this further.

A mood is typically a state of long duration: it may last for hours, days, or more. During that period, there is large number of objects which 'come one's way', and which differ not only in their shape and size, but also in their evaluative weight. In a state of gloom, for instance, a person might happen to listen to a jolly tune. While it would be incorrect to think that just by listening to the tune the person will snap out of his sad mood, it would also be wrong to claim that the person is unable to notice the life-affirmative air of that tune. However, decreeing that the jolly tune is the intentional object of the gloomy mood does not render the mood intelligible.

Perhaps the combination of the gloomy mood and the jolliness of the tune creates in the listener a feeling of sympathy for the vain efforts of his fellow humans, or an irritation with his uncultured neighbours for their choice of music. The arising of those emotions might be explicable by the concurrence of the negative mood and the perception of the jolly tune. What is not plausible though, is the explication of the particular mood by means of the representation of the jolly tune.

Given the wide variety in the evaluative profile of the objects in one's environment, the postulated intentional connection between mood and any object that happens to come one's way, fails to discharge the task of rationalizing explanation.

\section{Intentionality and Properties}

The third and most recent attempt to articulate an account of the intentionality of moods is presented not by reference to some object, either singular or plural, but in terms of their representational content. ${ }^{19}$ We are invited to think that what is represented during a mood occurrence is a property, as such: in an anxious mood, it is threatingness, in an irritable mood, it is offensiveness, in a mood of contentment, it is delightfulness, etc. The property represented by a mood is not attached to anything in particular: it is unbound. The proposal admits that moods appear to lack intentional object; but it claims that this lack does not deprive them of intentionality, since moods are states with a content which represents an unbound affective property.

That approach initially appears promising, since it sets a criterion for distinguishing emotions (which are directed at an intentional object), from moods (which are not thus directed), while acknowledging that each mood has a different character precisely because it involves a different mental content, due to the unbound property that it represents (scariness, offensiveness, delightfulness, annoyingness, etc.).

However, in my opinion, the proposal is problematic on conceptual grounds. More precisely, it is an account of intentionality that combines three conceptual confusions

${ }^{19}$ Mendelovic (2013) ( 2014). 
regarding the idea of an unbound affective property. Sorting out those confusions is a prerequisite for the sustainability of the account.

The first confusion concerns the notions of 'ordinary object' and 'intentional object'. I may love my cat (a living entity), admire a Nespresso machine (an artifact), hate the change in the weather (an event), wish for world peace (a state of affairs), reflect about rectangularity (a property), or wonder about the Ramsean restatement of Russell's paradox (a set of propositions). Simply put, an intentional object is whatever a mental state is about, or of, or directed at. But that at which the state is directed is not necessarily an 'object', if by that term one means a medium size three-dimensional thing.

The present representationalist proposal states that moods lack intentional object because they are about properties and not about objects; but that is obviously a problematic statement. Hence, the first problem for the representationalist is that from the alleged fact that moods are not about objects, in the ordinary sense, she infers that they lack intentional object altogether. However, the inference is invalid, since what makes something into an intentional object of mood is its correlation to that affective state, and not whether it is something that you have to pack when you move houses. ${ }^{20}$

The second confusion concerns the notions of 'affective property' and what we may call 'affect-related property'. The representationalist employs the notion of affective property to pick up a property not of the affect, but of that which is related to, and is represented by, the affect. The problem is that this way of expressing herself quickly leads to the confusion of the representational state with that which gets represented. Thus, the theory begins with the claim that a mood is intentional due to its representation of affective properties, such as scariness, theatingness, offensiveness, etc., and it concludes with the statement that in a mood we experience fear, joy, anxiety, but we don't experience anything as having these affective properties. ${ }^{21}$

To appreciate the confusion involved, we may observe that the notions of scariness, threatingness, offensiveness, etc., pick up a different type of properties from those denoted by the notions of fear, joy, anxiety, etc. One way to express the difference is by noting that the former notions (threatingness, etc.) characterize something at which a state is directed, while the latter notions identify the type of state (fear, etc.) that the subject is in. Another way, is to say that the former picks up a property of that which is represented in the content of the state, while the latter specifies the state in question. And yet another way to express the difference between properties like threatingness, and properties like fear, is that the former denote the 'objective pole' and the latter the 'subjective pole' of the affective state. Whichever manner we choose to articulate the relevant distinction, the fact is that the two types of properties fall into different categories, and thus lumping them together is very unhelpful and indicative of some conceptual entanglement.

The third confusion is of a different order, as it concerns a fundamental metaphysical issue. The representationalist claims that moods are intentional because they represent

\footnotetext{
${ }^{20}$ I used the simplest interpretation of the notion of 'object' to illustrate the problem, but the criticism applies whatever technical notion the representationalist might invoke. If by 'object' she means, for instance, an unqualified substratum, or a qualified substance, or a bearer of qualities, the point remains that something need not fall in those ontological categories to count as intentional object.

${ }^{21}$ Mendelovic (2013), ( 2014).
} 
unbound properties. But what exactly is an 'unbound property'? Unless the proponent comes clear on this issue, her proposal is hard to understand, and even harder to assess. At a minimum, we require a disambiguation of the meanings that may be involved in that notion. Here, I shall consider only the following three interpretations.

First interpretation: unbound is a property that is not bound to one particular substance. That is a claim easy to understand, because it is trivial. No property is ever bound to one particular substance, each property is in principle instantiable at more than one place at once, and that is why we often call objects particulars, and properties universals. $^{22}$ Therefore, if that is what the representationalist purports to claim, she may well drop the qualification 'unbound' and she may simply state that, according to her, moods are intentional because they represent affect-related properties of some object, situation, or state of affairs.

A second interpretation could be: unbound is a property that is not instantiated. If that is the meaning of the notion of 'unbound property', then it is hard to comprehend how someone can be in a particular affective state that represents a non-instantiated property. Notice that the representationalist does not claim that someone is in a particular affective state because that state represents that a certain property is not instantiated: that would be the representation of a fact (or of a state of affairs, or of a proposition), and our representationalist denies that this is the meaning she intends. ${ }^{23}$

A third interpretation might venture to focus not on what type of property an unbound property is but on how we might think of it: 'unbound' is a property thought of not as instantiated by an object, but thought of merely as a property. Again, that claim offers little help in making sense of what is distinctive about the representational content of mood, or indeed, of any affective state. Considering a property merely as a property appears to me to be a task for logical, conceptual, or metaphysical analysis; it is simply not clear why the representation of the properties of squareness, or of scariness, of triangularity, or of threatingness, represented - not as being (or soon to be) instantiated, neither as owned (or soon to be owned) by some object, nor as exemplified (or soon to be exemplified) by some situation, but-merely as properties, should have any affective significance at all.

\section{Conclusion}

Attending to the phenomena of mood raises a series of philosophical puzzles. It has been claimed that an appeal to the notion of intentionality could help us resolve those puzzles. Representationalists assert that focusing on intentionality is the key to our understanding of the phenomenal aspects of affective experience. They have accordingly put forward or endorsed several suggestions as to how we may think of the intentionality of moods. In my discussion, I looked at the most prominent of those suggestions, and found them problematic. My argumentation does not imply that

\footnotetext{
${ }^{22}$ I leave aside issues raised by haeccity: even if we were to admit such property in our ontology, it would not be of help to the current representationalist proposal, since it is a property bound, by definition, to some particular object.

${ }^{23}$ Mendelovic (2013), ( 2014).
} 
representationalism as such is doomed to failure; it does indicate, though, that intentionality, as understood by representationalists, might not be the best starting point for a philosophical account of mood phenomena.

\section{References}

Baier, A. (1990). What emotions are about. Philosophical Perspectives, 4, 1-29.

Ben-Ze'ev, A. (2000). The subtlety of emotions. Cambridge: MIT Press.

Byrne, A. (2001). Intentionalism defended. Philosophical Review, 110(2), 199-240.

Crane, T. (2013). The objects of thought. Oxford: Oxford University Press.

Crane, T. (1998). Intentionality as the mark of the mental. In A. O'Hear (Ed.), Contemporary issues in the philosophy of mind (pp. 136-157). Cambridge: Cambridge University Press.

De Sousa, R. (1987). The rationality of emotions. Cambridge: MIT Press.

De Sousa, R. (2004). Emotions: What I know, what I'd like to think I know, and what I'd like to think. In R. C. Solomon (Ed.), Thinking About Feeling, ed (pp. 61-75). Oxford: Oxford University Press.

De Sousa, Ronald (2010) 'Emotion' Stanford Encyclopedia of Philosophy, ed. Edward Zalta, http://plato. stanford.edu/archives/spr2013/entries/emotion/.

DeLancey, C. (2006). Basic moods. Philosophical Psychology, 19, 527-538.

Deonna, J. A. (2006). Emotion, perception and perspective. Dialectica, 60(1), 29-46.

Deonna, J. A., \& Teroni, F. (2012). The emotions: A philosophical introduction. New York: Routledge.

Dretske, F. (1995). Naturalizing the mind. Cambridge: The MIT Press.

Elgin, C. (1996). Considered Judgment. Princeton: Princeton University Press.

Fish, W. (2005). Emotions, moods, and intentionality. In G. Forrai \& G. Kampis (Eds.), Intentionality past and future (pp. 25-35). New York: Rodopi Press.

Frijda, N. (1994). Varieties of affect: Emotions and episodes, moods and sentiments. In P. Ekman \& R. Davidson (Eds.), The nature of emotion (pp. 59-67). Oxford: Oxford University Press.

Goldie, P. (2000). The emotions. Oxford: Oxford University Press.

Griffiths, P. E. (1997). What emotions really are: The problem of psychological categories. Chicago: The University of Chicago Press.

Harman, G. (1990). The Intrinsic Quality of Experience. In N. Block, O. J. Flanagan, \& G. Güzeldere (Eds.), The Nature of Consciousness (pp. 663-675). Cambridge: Mass.: The MIT Press, 1997.

Hatzimoysis (2003a) 'Emotional Feelings and Intentionalism' in Philosophy and the Emotions, ed. by A. Hatzimoysis. Cambridge: Cambridge University Press: 105-112.

Hatzimoysis (2003b). 'Analytical Descriptivism Revisited” Ratio, XV: 10-22.

Hatzimoysis (2011) 'Introduction' in Self-Knowledge, ed. by A. Hatzimoysis. Oxford: Oxford University Press, 2011: 1-8.

Kenny, A. (1963). Action, emotion and will. London: Routledge \& Kegan Paul.

Kind, A. (2014). The case against representationalism about moods. In U. Kriegel (Ed.), Current controversies in philosophy of mind (pp. 113-134). London: Routlegde.

Lormand, E. (1985). Towards a theory of moods. Philosophical Studies, 47, 385-407.

Lyons, W. (1980). Emotion. Cambridge: Cambridge University Press.

Mendelovici (2013) Intentionalism about moods. Thought 2: 126-136.

Mendelovici. (2014). Pure Intentionalism about moods and emotions. In U. Kriegel (Ed.), Current controversies in philosophy of mind (pp. 113-134). London: Routledge.

Neta, R. (2011). The nature and reach of privileged access. In A. Hatzimoysis (Ed.), Self-Knowledge (Vol. 2011, pp. 9-32). Oxford: Oxford University Press.

Nussbaum, M. (2001). Upheavals of thought. Cambridge: Cambridge University Press.

Price, C. (2006). Affect without object: Moods and objectless emotions. European Journal of Analytic Philosophy, 2, 49-68.

Prinz, J. (2004). Gut reactions: A perceptual theory of emotion. Oxford: Oxford University Press.

Rattcliffe, M. (2010). The phenomenology of mood and the meaning of life. In D. Zahavi (Ed.), The Oxford handbook of philosophy of emotion (pp. 349-372). Oxford: Oxford University Press.

Roberts, R. (2003). Emotions: An essay in aid of moral psychology. Cambridge: Cambridge University Press. Searle, J. (1983). Intentionality. Cambridge: Cambridge University Press. 
Siewert, C. (2012). Respecting appearances: A phenomenological approach to consciousness. In D. Zahavi (Ed.), The Oxford handbook of contemporary phenomenology (pp. 48-69). Oxford: Oxford University Press.

Siewert, C. (1998). The significance of consciousness. Princeton: Princeton University Press.

Sizer, L. (2000). Towards a computational theory of mood. British Journal for the Philosophy of Science, 51, 743-769.

Solomon, R. (1976). The passions. New York: Anchor Press.

Solomon, R. (1993). The passions: Emotions and the meaning of life. Indianapolis: Hackett.

Tappolet, C. (2000). Emotions et Valeurs. Paris: Presses universitaires de France.

Terroni, F. (2007). Emotions and Formal Objects. Dialectica, 61(3), 395-415.

Tye, M. (2002). Consciousness, Color and Content. Cambridge: MIT Press. 